\title{
Fluxo de informação no contexto contábil
}

\author{
Information flow in the accounting context
}

\author{
Elder Lopes Barboza \\ Doutorando em Ciência da Informação da UNESP. \\ E-mail: elderlopes@bol.com.br
}

Milene Martins Roa
Especialista em Gestão da Informação, do Conhecimento e Novas Tecnologias - IESF.
E-mail: milene@ @ novaaliancams.com.br

\section{Resumo}

A compreensão dos fluxos de informação contribui para o desenvolvimento organizacional em diversos setores. Diante disso, surge a necessidade de compreender como ocorre o fluxo de informação em uma empresa de contabilidade. Para isso, esta pesquisa objetivou investigar como ocorre o fluxo de informação dentro de uma empresa de contabilidade, identificando os tipos de informação que circulam na empresa, quem a produz, por quais setores transita essa informação, que processos são gerados e quais tecnologias são utilizadas. A metodologia utilizada se pautou na revisão da literatura para a discussão dos conceitos pesquisados, pesquisa documental que se deu por meio do acesso a sistemas e documentos relativos ao ambiente pesquisado, e levantamento de dados através de questionário para compreender o fluxo de informação dentro da empresa selecionada. Como resultados pela análise de dados, foi possível observar como ocorre o fluxo de informação na empresa pesquisada e como esse fluxo influencia na tomada de decisão.

Palavras-chave: Fluxo de informação. Tomada de decisão. Contabilidade.

\begin{abstract}
The understanding of information flows contributes to organizational development in its various sectors. Given this, the need arises to understand how the information flow occurs in an accounting firm. The purpose of this research was to investigate how the information flow occurs in an accounting firm, identifying the types of information that circulate in the company, who produces it, through which sectors this information is transported, which processes are generated and which technologies are used. The methodology used was based on the literature review for the discussion of the researched concepts, documentary research that was done through access to systems and documents related to the researched environment, and data collection through a questionnaire to understand the flow of information within the company selected. As results from the data analysis, it was possible to observe how the information flow occurs in the researched company and how this flow influences decision making.
\end{abstract}

Keywords: Information flow. Decision Making. Accountting. 


\section{Introdução}

A evolução tecnológica trouxe, dentre outras consequências, o fenômeno do caos informacional, em que se observa que em várias áreas existe uma confusão na troca de informações gerando um congestionamento em seu fluxo, deixando muito conteúdo à deriva. Os ambientes organizacionais dependem cada vez mais do fluxo de informação existente e disponível em seu meio de atuação.

Sendo assim, é preciso levar em conta o processo de coleta de informação que existe dentro da organização através do reconhecimento da verificação da mesma, seguida de sua mensuração e de sua qualidade, e ainda da evidenciação dessa informação que será transmitida aos usuários, e da objetividade do que foi transmitido. Para Floriani (2007, p. 35), "a gestão da informação requer o estabelecimento de processos, etapas sistematizadas, organizadas e estruturadas pelos quais os fluxos informacionais são responsáveis", desta forma facilitando o uso do fluxo.

No que concerne às informações contábeis que estão no centro da discussão em relação ao desenvolvimento nacional, considerando as características do país em relação à carga tributária e a necessidade constante em lidar com os impostos, taxas, legislação e manter a competitividade, a tecnologia passou a ser uma grande aliada, auxiliando as organizações por meio de sistemas cada vez mais complexos que conseguem catalizar informações necessárias ao desenvolvimento das atividades.

Porém, os programas utilizados no cotidiano contábil, que são, em sua maioria, vinculados à Receita Federal, mudam com muita rapidez, além do que, existem diferenças na legislação tributária entre os estados que contribuem para problemas voltados à tecnologia e à informação.

O momento atual é de uma sociedade que busca o desenvolvimento econômico, e devido a mudanças que ocorrem diariamente neste contexto, cada vez mais se torna necessária uma busca constante pela informação e a compreensão do fluxo de informação que ocorre nas organizações e setores.

Para entender a informação na área da contabilidade, é preciso compreender os processos que se estabelecem no contexto do fluxo de informação. Diante disso, a questão norteadora desta pesquisa definiu-se em: Como ocorre o fluxo de informação em uma empresa 
de contabilidade?

Para responder a questão de pesquisa, definiu-se como objetivo geral investigar como ocorre o fluxo de informação dentro de uma empresa de contabilidade. Como desdobramento do objetivo geral, estabeleceu-se como objetivos específicos: a) identificar os tipos de informaçãos que circulam no ambiente interno; b) identificar atores, setores, atividades, canais e tecnologias existentes na organização; c) descrever os processos existentes no fluxo de informação.

Quando a informação é tratada de forma correta é possível organizá-la de forma coerente e clara, passando a disponibilizá-la para que possa ser usada e, desta forma, o indivíduo consegue compartilhar seu conhecimento com todos a sua volta auxiliando na tomada de decisão e contribuindo para o desenvolvimento organizacional.

Para responder aos objetivos propostos, a metodologia utilizada neste trabalho amparou-se em uma revisão de literatura da área de Ciência da Informação e informação contábil, pesquisa documental e de campo com coleta de dados, bem como a aplicação de questionário na empresa selecionada, seguida da análise de dados e considerações.

\section{Fluxos de informação e sua presença no contexto organizacional}

O conceito de informação é tão complexo quanto o fenômeno que confere significado ou sentido às coisas a ele vinculado, considerando que ambos carecem estar nos respectivos contextos para que se possa definir e investigar suas propriedades e dinâmicas.

A informação pode ser considerada como dados já tratados, sendo assim possuidora de significado. A informação obtida através de um conjunto de dados pode variar de acordo com o contexto ou de quem está analisando. Os dados organizados transmitem uma mensagem de acordo com o fenômeno ou evento ocorrido, auxiliando na resolução de problemas existentes ou que venha a surgir em uma organização, aumentando o conhecimento sobre o assunto abordado (MCGEE; PRUSAK, 1994).

Para Rossini e Palmisano (2003, p. 43), “informações são dados configurados de forma adequada ao entendimento e a utilização pelo ser humano". Desta forma, a informação tem valor imenso dentro da organização, estando baseada nas rotinas diárias em função dos processos de negócios da empresa. 
As informações que são utilizadas nas organizações percorrem um processo que possui vários níveis. Para melhorar essa utilização é necessária a criação de estratégias eficazes para dinamizar a estrutura da informação no contexto da organização. Choo (2003) afirma que, para criar estratégias, é necessária a elaboração de processos que formam um ciclo contínuo, onde se encontram seis processos correlacionados entre si, sendo eles: Identificação das necessidades de informação (o que se precisa); aquisição da informação (onde buscar); organização e armazenamento da informação (onde e como guardar); desenvolvimento de produtos e serviços de informação (como aplicar); distribuição de informação (compartilhar com todos); e uso da informação (usufruir de forma eficaz).

Assim que a informação é contextualizada, é utilizado o conhecimento que se constrói a partir dela, quando se consegue,então, compreender o que as informações transmitem gerando mais do que significado, havendo assim, a utilização das informações de forma coerente. Através de um conjunto de informações interligadas e logicamente relacionadas pode-se tomar decisões mais acertadas, percebendo como funciona o ambiente de onde esta informação foi retirada, facilitando o entendimento.

O conceito de conhecimento é o ato ou efeito de conhecer através da informação adquirida por meio de estudo ou experiência. De acordo com Davenpont e Prusak (1999, p. 51), "quando o conhecimento para de evoluir, ele se transforma numa opinião ou num dogma" o que se torna prejudicial para uma organização. Sendo assim, se deve utilizar o conhecimento adquirido ou aperfeiçoado por cada indivíduo, para melhorar seu desempenho na execução do trabalho dentro da organização, fazendo com que cada um tenha crescimento intelectual e profissional, e melhorando a qualidade do serviço oferecido para o cliente.

Já para Laudon e Laudon (1999, p. 79), “Conhecimento é o conjunto de ferramentas conceituais e categorias usadas pelos seres humanos para criar, colecionar, armazenar e compartilhar a informação". Através do conhecimento obtido pela informação dentro da organização, podemos transformar a informação diária em um fluxo de informação ativo.

O significado da palavra fluxo compreende o ato de fluir, ou seja, o movimento contínuo, mas na definição figurada ou conceito utilizado para fluxo é a ocorrência de fatos, ideias e ações. Valentim e Teixeira (2012, p. 151) definem essa colocação do fluxo dentro das organizações da seguinte forma: "Os fluxos de informação são imbricados à própria estrutura organizacional, bem como existem a partir da dinâmica organizacional gerada por seus colaboradores, estes por sua vez são responsáveis pela geração de ideias, conhecimento e 
inovação que alimentam os sistemas de informação gerencial”.

O fluxo de informação pode ser trabalhado em três áreas de conhecimentos específicos. São utilizadas na semiótica, onde o fluxo atua na construção da semiose no processo interativo (MACHADO; ROMANINI, 2010); na teoria da informação, utilizada na área da matemática e de informática, são utilizados modelos desses segmentos (SHANNON; WEAVER, 1949); e na teoria da comunicação, onde o fluxo é presente nas organizações em sua política, cultura e comportamento nas elocuções no contexto da trasmissão de mensagem (FISKE, 2010).

Para ter um bom fluxo informacional é preciso que haja uma gestão de informação eficiente, para tratar a informação de forma que possa ser utilizada na tomada de decisão. Para Drucker (2002, p. 22), “em última análise, gestão significa a substituição de ideias por ação, do conhecimento por cultura e da cooperação por força", neste caso o autor fala da importacia da gestão da informação como meio de melhorar o fluxo informacional.

Desta forma, a organização que trabalha em conjunto, onde cada setor colabora com os demais, com o apoio de uma liderança que proporcione meios adequados de trabalho, com comunicação aberta a novas ideias, se cria uma equipe voltada para o desenvolvimento do fluxo de informação e para o próprio crescimento da organização.

A utilização do fluxo de informação de forma correta na tomada de decisão é um instrumento muito eficaz em qualquer organização, desde que a informação seja utilizada de forma estratégica, observando-se sua atuação nos três níveis, sendo: estratégico, tático e operacional. De acordo com McGee e Prusak (1994) o valor da informação é determinado pelo usuário, o qual implica que a mesma pode ser reutilizável. Com isso, percebe-se que a informação depende da análise de cada usuário.

Por meio do fluxo de informação é possível perceber como a informação está fluindo dentro de uma organização, se é utilizada de forma eficaz ou superficial e se tem sido base para a tomada de decisão.

O fluxo de informação pode ser utilizado na organização ao se levar em consideração que existem três tipos de fluxos que podem influenciar no processo em que as informações são trabalhadas. De acordo com Smit e Barreto (2002) existem três fluxos básicos de informação: primeiro o interno que consiste na capacitação, seleção, armazenamento e recuperação da informação; o segundo que consiste na transformação da informação em conhecimento; e o terceiro a transcrição da informação para uso, fazendo com que o fluxo de informação se 
apresente de forma distinta em dois níveis: o interno e o externo.

Cada organização tem realidades distintas, tendo seu fluxo variável de acordo com seu segmento de atuação. Para Floriani (2007), existem três modelos de fluxos adequados para implantação nas organizações de acordo com sua atuação.

O fluxo interno e externo da informação: consiste na criação da informação por meio de ideias que se transformam em informação de acordo com a prioridade da empresa, passando pelo sistema de armazenamento e recuperação da informação onde ocorre a seleção e classificação, e chega à realidade onde a informação se converte em conhecimento.

São três as etapas de fluxos das informações: A primeira são os fluxos de informações coletadas no ambiente externo da organização que possam ser utilizadas internamente; A segunda é o fluxo de informação externo que engloba as informações produzidas dentro da própria organização de acordo com suas perspectivas; e a terceira corresponde ao fluxo de informação criado pela organização e liberado para o ambiente externo, para o mercado através de colaboradores, clientes ou disponibilizado em sites.

O modelo de representação do fluxo da informação envolve sete etapas do fluxo informacional, sendo: a identificação da necessidade da informação, a obtenção, o tratamento, a distribuição, o uso, o armazenamento e o descarte. Através destas etapas a organização tem facilidade em manter seu fluxo ativo com informações realmente necessárias e vigentes, não acumulando informações desnecessárias (BEAL, 2008).

O fluxo de informação usado de forma abrangente dentro de uma organização ajuda a superar barreiras que surgem no decorrer da prestação de serviço de forma rápida e evitando possíveis problemas, para compreender como é utilizado o fluxo de informação, será analisado seu uso dentro de uma empresa de contabilidade, mas antes deve se entender como ocorre a distribuição de informação na área contábil. 


\section{A informação contábil: conceitos e aplicações}

Para compreender as informações contábeis é preciso saber que a história da contabilidade é tão antiga quanto da própria civilização. Surgiu da necessidade de perpetuação e interpretação dos fatos ocorridos, como forma de dispor das informações precisas. Isto é, a origem da contabilidade está ligada ao movimento do comércio que ocorria entre várias cidades da antiguidade, havendo a necessidade que se fizessem registros sobre os bens, produtos, quem comprava e como pagava, entre outras informações. Com o surgimento do papel e da pena, o registro das informações comerciais ficou mais fácil de ser feito.

Foi preciso, então, conhecer as reais possibilidades de uso, de consumo e de produção existente, bem como fazer a guarda de tantas informações, por meio de registros, tornando assim a contabilidade mais do que mero registro e sim um instrumento de gestão. As práticas e teorias contábeis ganharam importância com o surgimento das multinacionais que precisavam transmitir informações contábeis para os acionistas de forma clara e coerente.

A informação contábil tem por objetivo o estudo das variações, tanto quantitativa como qualificativa do patrimônio. Por meio destas informações úteis que se formam os resumos e que, por meio de relatórios, são transmitidas pelo contador para seus clientes auxiliando na tomada de decisão. A contabilidade trabalha com diversos tipos de informações, como a informação econômica, financeira, tributária, de acordo com o enquadramento específico da empresa e da necessidade de cada cliente.

As informações obtidas pelo contador através de seu cliente tem que ter alguns critérios, para que a tomada de decisão seja a mais precisa possível e de forma rápida. Conforme Yamamoto e Salotti (2006, p. 5):

[...] a informação contábil pode ser considerada como aquela que altera o estado da arte e do conhecimento de seu usuário em relação à empresa e, a partir de interpretações, a utiliza na solução de problemas, sendo a natureza da informação contábil, entre outras, econômico-financeira, física e de produtividade, assim a informação contábil tem como consequência a ratificação ou alteração da opinião de seus usuários a respeito das atividades da empresa.

É possível perceber a importância da utilização do fluxo informacional dentro da organização contábil, pois se baseia nas informações que recebem do contador, e a partir delas são realizadas as decisões aplicadas na empresa, que podem ser positivas ou negativas de acordo com sua veracidade. O fluxo de informação contínuo tanto externo como interno e a colaboração existente são necessários para o bom desenvolvimento da contabilidade. 
As informações contábeis internas são geridas dentro da organização através de relatórios próprios por meio de sistemas automatizados ou de dados coletados dos sites governamentais e dados fornecidos pelo cliente. Já as informações contábeis externas são transmitidas através de sistema para o governo, que monitora as empresas, como por exemplo, para saber se as mesmas cumprem as obrigações correspondentes. As informações transmitidas aos clientes se transformam em conhecimento que é utilizado para a tomada de decisão e melhoramento da organização. Smit e Barreto (2002, p. 16) reconhecem nessa dinâmica ao afirmar que "é o mundo do gerenciamento e controle da informação".

A informação financeira tem suas particularidades, usando de métodos específicos para gerar informações que são transmitidas para os acionistas ou sócios. A contabilidade financeira acaba interligando todos os pontos da contabilidade em uma só. Como Gouveia (1978, p. 28) afirma, “a contabilidade é uma arte. É a arte de registrar todas as transações de uma companhia que possam ser expressas em termos monetários. E é também a arte de informar os reflexos dessas transações na situação econômico-financeira dessa companhia”.

Os fluxos de informação financeira ou informações de natureza econômica abrangem a receita e a despesa que define o lucro ou prejuízo existente. Essas informações são utilizadas tanto por usuários internos como externos. A informação financeira tem por objetivo demonstrar informaçãos que envolvem a situação econômica, as alterações e os resultados das operações, com a finalidade de ser útil a investidores, a credores e outros usuários, que estejam interessados em fazer investimentos de forma racional, seja oferecendo crédito ou na tomada de decisão, colaborando assim com o funcionamento do mercado.

As informações financeiras devem ser compreensíveis aos utentes interessados para que possam ajudar a executar e a cumprir as responsabilidades do planejamento, bem como o auxílio do controle de tomada de decisão. Quanto melhor forem as informações financeiras obtidas, mais claras e decisivas serão as decisões tomadas.

Para que as informações financeiras tenham uma adequada utilização, elas devem possuir algumas características, que juntamente com os conceitos, princípios e normas contabilísticas fazem com que tenham veracidade e resultados adequados. Essas características conforme Fabretti (1997) cita são: Relevância; Confiabilidade ou fiabilidade; Comparabilidade.

Na Relevância, as informações devem ser úteis de acordo com as necessidades dos utentes na tomada de decisão. Desta forma as informações são consideradas relevantes e 
materiais quando influencia nas decisões financeiras, econômicas, em algum instante, auxiliando a avaliação do impacto dos fatos ocorridos no passado, presente ou futuro, confirmando assim as decisões tomadas ou oferecendo oportunidade de corrigirem decisões anteriores. Através das informações relevantes obtidas os usuários podem analisar o passado com clareza e projetar melhor o desempenho para o futuro, à medida que seus compromissos ficam mais definidos, como melhorar os preços, aumentar o valor das ações, formas de pagamento entre outros.

Sobre Confiabilidade ou fiabilidade, para que possa ser utilizada a informação de maneira correta ela deve ser confiável, não devem conter erros, desvios substanciais ou vieses relevantes ao que a informação deve representar, mantendo-se fiel ao que foi proposto. A informação pode ser relevante para o usuário, mas isso não significa que seja confiável em sua natureza ou divulgação. Um exemplo são as informações "falsas" que circulam na internet. Sendo assim, para que a informação seja confiável devem ser obtidas de fontes seguras e em tempo hábil. A confiabilidade é atributo que se fundamenta com a veracidade para a tomada de decisão pelos utentes.

Quanto à comparabilidade, deve-se favorecer ao usuário a comparação das informações de sua organização ao longo do tempo, com o objetivo de identificar tendências em sua colocação financeira e no desempenho obtido. Assim os utentes serão capazes de comparar os dados contábeis em vários momentos diferentes verificando qual o melhor posicionamento financeiro. A principal característica qualitativa da comparabilidade é a elaboração das demonstrações contábeis financeiras que devem ser apresentadas a qualquer mudança ocorrida, fornecendo informações suficientes para perceberem diferenças de um período para outro.

Existem várias características qualitativas que são utilizadas na contabilidade, porém essas três características específicas são mais usadas no campo da informação contábil financeira, de forma mais abrangente do que as demais. De acordo com Wang, Ziad e Lee (2000, p. 98) as características das boas informações são descritas da seguinte forma: “Acuracidade, objetividade, credibilidade, reputação, acessibilidade, segurança no acesso, relevância, valor agregado, temporalidade, integridade, quantidade de informação apropriada, interoperabilidade, representação concisa, representação consistente, facilidade de manipulação".

Os autores abordam ainda as características da qualidade da informação de forma mais ampla, assim como outros autores utilizam termos diferentes para definirem a mesma 
necessidade em relação às informações financeiras que devem ser dispostas para o usuário como forma de auxílio para tomada de decisão. Outro aspecto de informação que os usuários devem ter acesso são as informações tributárias.

A contabilidade tem várias vertentes específicas e uma delas é a contabilidade tributária que tem como objetivo principal os tributos, que são fatos gerados através de informações obtidas das empresas e lançadas adequadamente em sistema ou site, incidindo sobre o lucro ou faturamento mensal, gerando os tributos principais de acordo com a natureza das informações podendo ser referente à União, ao Estado ou Município. Fabretti (1997, p. 25) define o conceito de contabilidade tributária da seguinte maneira:

O ramo da Contabilidade que tem por objetivo aplicar na prática conceitos, princípios e normas básicas da contabilidade e da legislação tributária, de forma simultânea e adequada, deve também demonstrar à situação do patrimônio e o resultado do exercício, de forma clara e precisa, rigorosamente de acordo com os conceitos, princípios e normas básicas de contabilidade. O resultado apurado deve ser economicamente exato.

O autor demonstra como a contabilidade trabalha seus conceitos e princípios de forma a obter resultados exatos e, sendo assim, a legislação brasileira trabalha com as seguintes formas de tributação: Simples Nacional; Lucro Presumido; Lucro Real.

As empresas enquadradas no Simples Nacional não podem ultrapassar o faturamento de R\$ 2.400.000,00. Os tributos são pagos em uma única guia mensal, os tributos variam de alíquota conforme sua receita nos últimos 12 meses, podendo ser elevada de 3\% a 19,65\% sendo uns dos benefícios que o governo oferece entre outros. A empresa que se enquadra no Lucro presumido diferencia-se pelo tributo do IRPJ (Imposto de Renda de Pessoa Jurídica) e a CSLL (Contribuição Social sobre o Lucro Líquido) que é calculado sobre o faturamento conforme a porcentagem estabelecida pelo governo podendo variar de acordo com atividade ou ramo do comércio e prestação de serviço da empresa, os demais tributos seguem a legislação tributária. Já as empresas que optam pelo Lucro Real, pagam os tributos citados acima conforme o lucro da empresa que é calculado após serem reduzidas todas as despesas e custos, os outros tributos vigoram a legislação tributária.

No Brasil existem diversos tributos a serem pagos pelas empresas podendo chegar a mais de 50 tipos de tributos diferentes entre impostos, taxas, contribuições de melhoria como, por exemplo, o combate à pobreza, contribuições sociais que as organizações estão sujeitas a pagar independente do porte da empresa. Os tributos mais comuns a todas as empresas são: INSS - contribuição previdenciária a cargo de pessoa jurídica; IPI - imposto sobre produtos 
industrializados; COFINS - contribuição para financiamento da seguridade social; PIS programa de integração social; CSLL - contribuição social sobre o lucro líquido; IRPJ imposto de renda das pessoas jurídicas; ICMS - imposto sobre a circulação de mercadorias; ISS - imposto sobre serviço de qualquer natureza.

Alguns tributos variam de acordo com a organização; há outros a serem pagos ou tendo benefícios concedidos de acordo com a legislação tributária, existindo diferenças na porcentagem das alíquotas para cálculo como também no código que deve ser emitido o tributo. Também frequentemente ocorrem alterações nas legislações tributárias que deixam o sistema tributário do país muito complexo.

Por este motivo a contabilidade tributária deve ser aplicada de forma eficaz. Para que isso possa acontecer, as organizações devem trabalhar em conjunto com a contabilidade por meio do planejamento tributário que fará um levantamento de qual regime tributário a empresa se encaixa de acordo com a legistação e quais tributos e benefícios terão direito; e o planejamento contábil que funciona através dos dados contábeis existentes e das informações trocadas entre o cliente e o contador. Conforme Oliveira (2004, p. 39) demonstra:

Qualquer que seja a forma de tributação escolhida pela empresa pode-se verificar que a falta de planejamento estratégico tributário pode deixar a empresa mal preparada para os investimentos futuros, devido a uma possível insuficiência de caixa, gerando um desgaste desnecessário de investimento forçado para cobertura de gastos que não estavam previstos.

Desta forma, observa-se a importância que a contabilidade exerce nas organizações, sabendo que os tributos são uma obrigação criada por lei para arrecadação do governo como forma de obter renda para o desenvolvimento e manutenção dos serviços oferecidos à população, porém um erro obtido na contabilidade tributária pode acarretar em impostos mais caros ou omissão de informação perante o órgão púbico em relação à organização.

Diante de toda a discussão, é possível perceber as conexões entre os fluxos de informação e a contabilidade, cujos conceitos têm na informação tributária a ocorrência dos fenômenos informacionais, sendo sua investigação necessária ao desenvolvimento organizacional. Com isso, apresenta-se metodologia utilizada na pesquisa e, posteriormente, os resultados alcançados. 


\section{Metodologia}

Para elaboração desta pesquisa utilizou-se da revisão da literatura para discutir teoricamente sobre fluxo informacional em organizações e sobre informação contábil. Também se utilizou de pesquisa documental, para analisar as informações que se encontram disponíveis na empresa por meio de sistema informático, planilhas e documentos técnicos, bem como de uma pesquisa de campo para coleta de dados, que, com a autorização devida, foi aplicado questionário para investigar como ocorre o fluxo de informação dentro da empresa selecionada. Os dados de identificação dos respondentes foram mantidos em sigilo.

Foi selecionada, como universo de estudo, uma empresa de contabilidade estabelecida em Campo Grande - MS, que atua desde 1989 na prestação de serviços no ramo da contabilidade com objetivo de oferecer assessoria às organizações empresariais e efetuando serviços referentes às obrigações legais.

A empresa tem uma estrutura hierárquica tradicional com característica familiar, e no momento da pesquisa contava com dois sócios, um colaborador e quatorze funcionários de diversos setores. Atualmente, presta serviço para duzentas empresas de vários segmentos e regimes tributários diferentes, com um nível de informação alto para suprir as necessidades dos clientes. Para um melhor entendimento da organização apresentamos a seguir a estrutura organizacional: 
Figura 1 - Estrutura organizacional da empresa

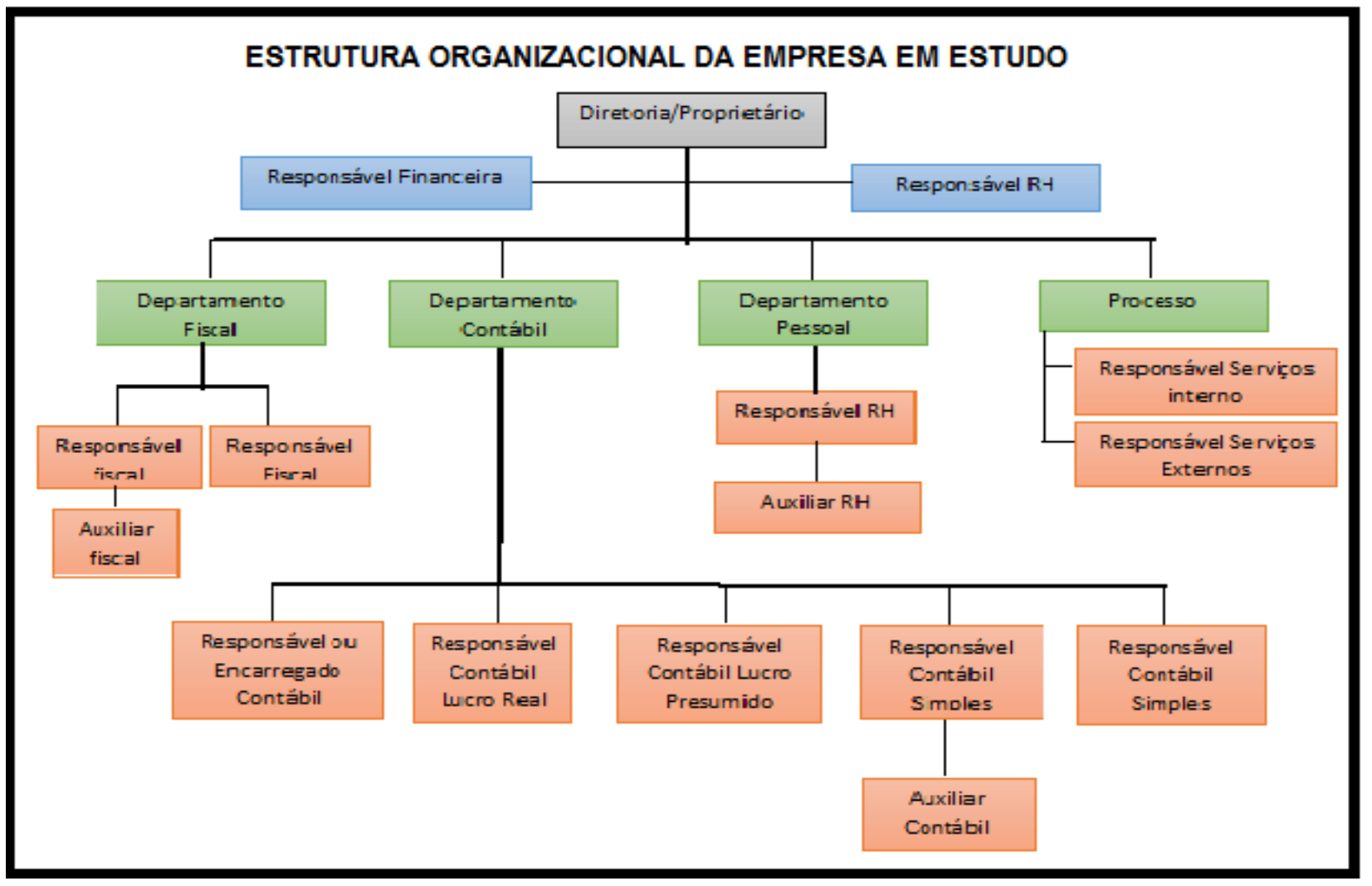

Fonte: Elaborado pelo autor.

De acordo com a estrutura da empresa ilustrada acima, é possível identificar cada setor e a forma hierárquica existente. Inicialmente, na Diretoria se encontra o responsável legal da empresa que está ligada diretamente aos proprietários das empresas/clientes. É o setor que identifica o serviço que será prestado, estipula o valor a ser pago, orienta os clientes sobre o regime tributário que melhor se encaixa a empresa, se deve haver alguma mudança na forma contábil de processar os dados das empresas e, além disso, é quem entra em contato com os fiscais. Quando necessário transmite informações aos funcionários sobre a situação das empresas, direcionando o que deve ser feito e permitindo aos funcionários entrar em contato com os clientes e deixá-los cientes de tudo que ocorre referente ao seu estabelecimento, mantendo contrato com atendimento de pessoas físicas e jurídicas, comunicando aos demais setores apenas o que for necessário, sendo o representante legal/proprietário responsável pela administração de forma geral da empresa e seu bom funcionamento.

No setor financeiro encontra-se o sócio minoritário que é o filho do dono e responsável pela emissão e cobrança dos boletos bancários dos clientes, tendo a responsabilidade de pagamentos referentes às despesas do escritório como pagamentos de funcionários, pagamento do programa utilizado pela empresa na prestação de serviço, pagamento do suporte técnico, 
serviço de prestação de informação tributária (Infolex) entre outras, como também das demais contas e recebimentos. O responsável fica a frente da administração financeira devendo analisar os créditos e débitos existentes e os certificados digitais das empresas, repassando informações pertinentes para o responsável legal. Em muitos casos estabelece contato com os clientes oferecendo suporte no atendimento, passando informações aos demais funcionários sobre as necessidades dos clientes ou sobre algum serviço que deva ser elaborado; muitas vezes exerce a função de gerente da empresa e é quem mais tem contato com os funcionários de forma geral.

No setor de recursos humanos da empresa o responsável também é sócio minoritário, sendo ele quem responde pela parte burocrática da contratação, demissão, folha de pagamento, holerite, férias, folgas, escala de quem trabalha quando há feriados prolongados (feriado que acontece na terça ou quinta, e o funcionário utiliza o banco de horas para folgar na segunda ou sexta), a fim de que nenhum setor fique desfalcado no suporte ao cliente. Incumbe-se, também, de informar aos funcionários sobre as questões legais referentes aos direitos e deveres do colaborador, trabalha diretamente com a diretoria auxiliando no que for solicitado e transmitindo mudanças ou informações para os clientes.

O próximo setor mencionado é o departamento fiscal onde há dois responsáveis e um auxiliar, ambos são responsáveis por uma quantidade específica de empresas, o encarregado que conta com um auxiliar tem um número maior de clientes, os dois responsáveis trabalham com empresas de todos os regimes tributários, já o auxiliar faz a escrituração das empresas que se enquadram no regime do Simples Nacional, fazendo a transmissão das obrigações nos receptivos programas, faz a escrituração, levantamento de compra, vendas e despesas passando o valor do faturamento, bem como as demais informações sobre o que foi feito durante o mês para seu encarregado. Costuma trocar ideias/informações com todos os setores e presta serviço para o diretor e responsável financeiro.

Os responsáveis fiscais fazem a escrita das suas empresas correspondentes, como as guias de impostos a serem pagos, transmissão das obrigações junto aos órgãos públicos através de sites ou programas específicos, sempre atentando para que seja feito dentro do prazo para não gerar multa. Também informa aos clientes sobre as questões tributárias que dizem respeito a cada empresa de acordo com o regime que se enquadram ou alterações que devam ser feitas, todos os funcionários do setor buscam informações no site da Secretaria da Fazenda, na consultoria do sistema utilizado, em sites de área contábil, e transmitem as informações correspondentes às empresas para o proprietário e para o responsável financeiro. 
Quanto ao setor do departamento contábil, este conta com um responsável/encarregado, quatro responsáveis e um auxiliar. Como no departamento fiscal, cada responsável tem suas empresas específicas para elaborar seu trabalho, e o encarregado tem a função de supervisionar o serviço que cada um faz e ajudar quando for necessário, e é quem transmite ao proprietário informações sobre o desenvolvimento do trabalho. No caso do setor contábil, cada responsável trabalha com um regime tributário específico, faz o fechamento do balanço e demais documentos necessários a contabilidade. Somente as empresas do Lucro Real e Presumido tem prazo para apresentação de informações através de arquivos em programas do governo. As informações contidas no setor contábil são repassadas aos proprietários das empresas, e para bancos e órgãos públicos quando solicitados; existe troca de dados/informações entre responsáveis e clientes e o responsável financeiro e legal do escritório. O auxiliar fica a disposição do setor, ajudando a fazer lançamentos contábeis, trabalhando de acordo com a necessidade do cliente ou prazo para entrega das obrigações.

O Departamento Pessoal conta com um responsável pelo RH e um auxiliar, que ficam incumbidos de fazer o fechamento da folha de pagamento com os impostos referente à área, verificar as faltas, elaborar os documentos para contratação do funcionário, pagamento de salários, férias, licença médica, $13^{\circ}$ Salário, organização dos horários de trabalho ou hora extra e rescisão contratual dos funcionários. Sempre trocam informações com os clientes e responsável financeiro.

E por último o Setor de Processos, que possui dois funcionários para fazerem serviços burocráticos internos junto aos órgãos públicos, sendo através de telefone ou online na solicitação de protocolos, requerimentos, alterações contratuais, sempre em contato com os clientes e com o responsável financeiro e legal do escritório, havendo troca de informação com os demais funcionários sobre a situação da empresa; o responsável pelo serviço externo é quem vai aos órgãos públicos para resolver pendências dos clientes.

Para facilitar todo o procedimento, a empresa utiliza um sistema de informação próprio, chamado DOMÍNIO da Thomson Reuters para a execução dos serviços prestados, como sistemas disponíveis em sites governamentais e da Receita Federal que são alimentados por informações inseridas pelos funcionários. Também utiliza de uma prestadora de informações tributárias, a Infolex, para esclarecimento de dúvidas e cursos para atualização.

O questionário foi entregue para dez funcionários da empresa de contabilidade e obteve a participação de oito respondentes. O questionário conforme apêndice $\mathrm{A}$, foi constituído de 
dez perguntas abertas voltadas a investigar como fluem as informações existentes na organização. De acordo com Lakatos e Marconi (1999, p. 100), questionário é “instrumento de coleta de dados constituído por uma série de perguntas, que devem ser respondidas por escrito".

Descrita a metodologia com suas características, instrumentos e universo, a próxima seção se dedica a apresentar e discutir os resultados obtidos, de modo a verificar o cumprimento dos objetivos e respostas às indagações elaboradas, motivadoras dessa pesquisa.

\section{Resultados e análises dos dados}

Para definir como o fluxo de informação ocorre na empresa selecionada foi aplicado um questionário para dez funcionários da empresa, sendo que oito participantes responderam ao questionário.

Em relação ao perfil dos participantes foi possível obter os seguintes resultados, através das questões 1 e 2: "qual cargo/função exerce na empresa? E quais atividades são realizadas na organização?”. Apresentaremos os dados tabulados das questões no quadro abaixo.

Quadro 1: Perfil do entrevistado

\begin{tabular}{|c|l|l|}
\hline Participantes & Função/cargo & Atividades desempenhadas/realizadas \\
\hline 1 & $\begin{array}{l}\text { Encarregada do departamento } \\
\text { pessoal }\end{array}$ & Folha de pagamento \\
\hline 2 & Aux. de departamento pessoal & Emissão de folha de pagamento \\
\hline 3 & Aux. de escritório & Lançamentos contábeis \\
\hline 4 & Aux. administrativo & Abertura de empresas, apuração e resultados. \\
\hline 5 & Administrativo e contábil & Serviços administrativos, levantamento contábil e declarações. \\
\hline 6 & Aux. contábil & Emissão de guias mensais, declarações etc. \\
\hline 7 & Assistente de contabilidade & Serviço de contabilidade \\
\hline 8 & Encarregado pela escrita fiscal & Entrada/saída/apuração e imposto \\
\hline
\end{tabular}

Fonte: Elaborado pelo autor.

No quadro 1 demonstra-se o cargo e as atividades desenvolvidas pelos colaboradores. De acordo com o levantamento os participantes foram genéricos em relação às atividades que desempenham. Pela análise observamos que cada funcionário desenvolve suas funções de acordo com seu cargo.

Após definir o perfil dos participantes será analisada a importância da informação contábil para a realização do trabalho em cada função. Através da questão 3 a seguir: "Tem relação com organização/pessoas externas à empresa? Quais? Que tipo de informações são trocadas, com essas organizações/pessoas?”. Dos 8 participantes, apenas o participante seis não tem contato fora da empresa, os 7 participantes responderam de forma positiva, já os 
participantes quatro, cinco e oito foram mais abrangentes em suas respostas e os participantes um, dois, três e sete responderam de forma genérica. Na sequência será apresentada a resposta que sintetiza a opinião dos participantes:

\begin{abstract}
"Sim, clientes das organizações, órgãos públicos, através de contato por telefone, via e-mail e pessoalmente, onde tratamos do fluxo de informação da empresa sobre o serviço que necessita ser desenvolvido durante o mês com objetivo de verificar novas solicitações ou mudanças ocorridas para elaboração do trabalho, e com pessoas da área quando surgem dúvidas sobre algum assunto que não ficou bem esclarecido no intuito de sanar as dúvidas e sempre colocar nossos conhecimentos em discussão de forma a melhorar cada vez mais". (Participante 5)
\end{abstract}

A opinião dos demais participantes foi similar, ou seja, todos concordam que existe contato externo de maneiras diferentes, diretamente ou indiretamente, mas que não há como executar o trabalho de maneira adequada sem um intercâmbio.

Em seguida a tabulação da questão 4: "Quais as fontes de informações utilizadas pela organização? Quem busca pelas informações usadas? De que maneira realizam as buscas?” Os participantes responderam da seguinte maneira:

Quadro 2: Fontes de informação

\begin{tabular}{|c|l|l|l|}
\hline Participantes & $\begin{array}{l}\text { Quais as fontes de informações } \\
\text { utilizadas pela organização? }\end{array}$ & $\begin{array}{l}\text { Quem busca pelas } \\
\text { informações usadas? }\end{array}$ & $\begin{array}{l}\text { De que maneira realiza } \\
\text { as buscas? }\end{array}$ \\
\hline 1 & Internet, livros e cursos. & Não respondeu & Não respondeu \\
\hline 2 & $\begin{array}{l}\text { Informativos, jornais, cursos e } \\
\text { internet. }\end{array}$ & $\begin{array}{l}\text { Eu, colegas de trabalho, } \\
\text { proprietário. }\end{array}$ & Através de sites indicados. \\
\hline 3 & $\begin{array}{l}\text { Internet como sites contábeis e } \\
\text { órgãos }\end{array}$ & Não respondeu & Não respondeu \\
\hline 4 & $\begin{array}{l}\text { Site Receita Federal, Secretaria do } \\
\text { Estado, Prefeitura municipal. }\end{array}$ & $\begin{array}{l}\text { Cada um busca o que } \\
\text { precisa. }\end{array}$ & Não respondeu \\
\hline 5 & $\begin{array}{l}\text { Site de pesquisa (IOB, Infolex, } \\
\text { outros). }\end{array}$ & $\begin{array}{l}\text { Não respondeu } \\
\text { Estado, documentos da empresa e } \\
\text { usuários das empresas. }\end{array}$ & $\begin{array}{l}\text { Não respondeu } \\
\text { palavras chaves. }\end{array}$ \\
\hline 6 & $\begin{array}{l}\text { Documentos, internet e cliente. } \\
\text { Site Receita Federal, prefeitura, por }\end{array}$ & $\begin{array}{l}\text { Faço as buscas pelas } \\
\text { informações }\end{array}$ & $\begin{array}{l}\text { Por } \\
\text { documentos, leis. }\end{array}$ \\
\hline 8 & $\begin{array}{l}\text { Sites de órgãos públicos, } \\
\text { documentos das empresas, próprio } \\
\text { sistema etc. }\end{array}$ & $\begin{array}{l}\text { Usuários, clientes, todos } \\
\text { que precisam das } \\
\text { informações disponíveis. }\end{array}$ & $\begin{array}{l}\text { Através de buscadores que } \\
\text { estão dispostos nos sites. }\end{array}$ \\
\hline
\end{tabular}

Fonte: Elaborado pelo autor.

De acordo com as respostas acima percebemos que todos sabem quais as fontes que podem ser utilizadas para buscar as informações necessárias para a elaboração de documentos, e o que mais for preciso. Referente a quem busca a informação quatro participantes não responderam, mas é possível considerar que cada funcionário faz suas buscas de acordo com sua necessidade e que a informação fica disponível a todos. Em relação à forma que são feitas as buscas, quatro participantes não responderam, já os participantes dois, cinco, sete e oito 
afirmaram que utilizam métodos próprios para realizar suas buscas sem nenhuma padronização.

No que diz respeito à questão 5: "Quais os tipos de informação são utilizados e produzidos no seu dia-a-dia?”, obeteve-se as seguintes respostas:

Quadro 3: Tipos de informação

\begin{tabular}{|c|c|c|}
\hline Participantes & Setores & Tipo de Informação \\
\hline 1 & \multirow[b]{2}{*}{$\begin{array}{l}\text { Departamento } \\
\text { pessoal; }\end{array}$} & \multirow{2}{*}{$\begin{array}{l}\text { Se houve admissão ou demissão, funcionário vai sair de férias, se há falta ou } \\
\text { algum desconto a ser feito, para produção da folha de pagamento, holerite, } \\
\text { registro ou rescisão, gerar guias previdenciárias. }\end{array}$} \\
\hline 2 & & \\
\hline 3 & \multirow{4}{*}{$\begin{array}{l}\text { Departamento } \\
\text { Contábil; }\end{array}$} & \multirow{4}{*}{$\begin{array}{l}\text { Informação referente à vida financeira do cliente, para produção de balanço } \\
\text { patrimonial, balancete, DRE, Coeficiente de análise. }\end{array}$} \\
\hline 5 & & \\
\hline 6 & & \\
\hline 7 & & \\
\hline 4 & Administrativo; & $\begin{array}{l}\text { Utiliza todas as informações existentes aos clientes, para produzir } \\
\text { informações da situação atual da empresa perante aos órgãos públicos. }\end{array}$ \\
\hline 8 & $\begin{array}{l}\text { Departamento } \\
\text { fiscal; }\end{array}$ & $\begin{array}{l}\text { Necessita das informações sobre compra, venda, aquisições de serviço dos } \\
\text { clientes com finalidade de fechar o faturamento da empresa, e produzir as } \\
\text { guias de impostos mensais e transmitir as informações aos órgãos. }\end{array}$ \\
\hline
\end{tabular}

Fonte: Elaborado pelo autor.

Como é possível observar no quadro 3 as informações utilizadas pelos setores são transmitidas pelos clientes, inseridas no sistema e produzidas novas informações que fazem parte das atribuições das empresas, ou para auxiliar na busca de acordo com as necessidades existentes.

Após analisar os tipos de informações apresenta-se a questão 6: "A quem se destinam essas informações e quais canais de comunicação são utilizados? Que tecnologias utilizam no seu dia-a-dia para suas atividades?”. As respostas estão descritas no Quadro 4:

Quadro 4: Fluxo externo: Receptor, Canais e tecnologias

\begin{tabular}{|c|c|c|c|}
\hline Participantes & $\begin{array}{l}\text { Para quem vai } \\
\text { à informação? }\end{array}$ & $\begin{array}{l}\text { Quais os canais de comunicação } \\
\text { utilizados? }\end{array}$ & Quais as tecnologias utilizadas? \\
\hline 1 & \multirow{8}{*}{ Clientes } & $\begin{array}{l}\text { E-mail, telefone, pessoalmente } \\
\text { (reunião). }\end{array}$ & Internet, software, programas online. \\
\hline 2 & & E-mail, telefone, correspondência. & Computador, internet, software. \\
\hline 3 & & Telefone, E-mail. & $\begin{array}{l}\text { Computador, } \\
\text { multifuncional. }\end{array}$ \\
\hline 4 & & $\begin{array}{l}\text { E-mail, telefone, reunião, } \\
\text { correspondência. }\end{array}$ & $\begin{array}{l}\text { Software, programas do sistema e } \\
\text { online, computadores, internet. }\end{array}$ \\
\hline 5 & & E-mail, correspondência, telefone. & Internet, programas, sistemas. \\
\hline 6 & & E-mail, telefone. & Programas online, software, internet. \\
\hline 7 & & Correspondência, telefone, e-mail. & $\begin{array}{l}\text { Impressora multifuncional, internet, } \\
\text { sistema, programas. }\end{array}$ \\
\hline 8 & & Telefone, e-mail, reunião. & $\begin{array}{l}\text { Sistema, programa online, internet, } \\
\text { software impressora. }\end{array}$ \\
\hline
\end{tabular}

Fonte: Elaborado pelo autor.

Observamos que as informações são enviadas principalmente para os clientes por meio 
dos respectivos participantes, e o foco da informação gerada é para o desenvolvimento das empresas. Os canais de comunicação entre os participantes e clientes são demonstrados no quadro acima, assim como as tecnologias utilizadas. Em ambas, as respostas não foram muito especificas/detalhadas quanto a tecnologias e canais de comunicação, sendo as respostas simples e objetivas.

Em seguida demostra-se através da figura 2 como o procedimento da informação tratado na questão 6 ocorre:

Figura 2 - Fluxo de informação externo: Receptor, canais e tecnologias.

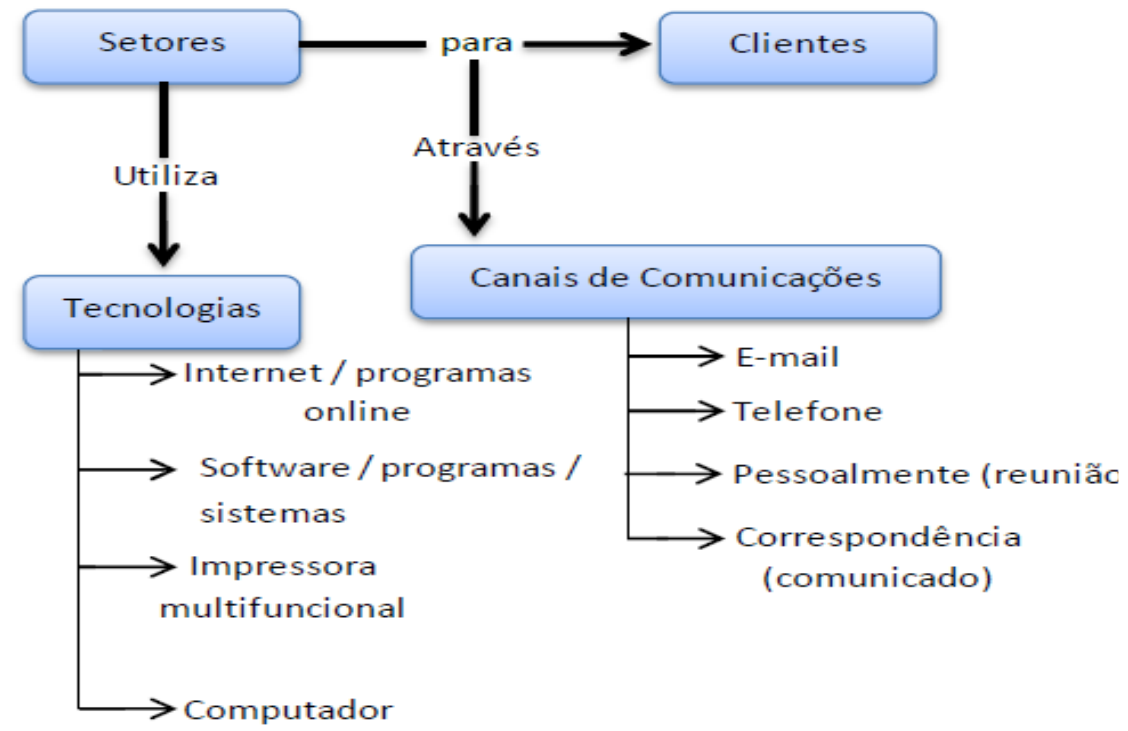

Fonte: Elaborado pelo autor.

Continuando com a análise dos resultados, apresenta-se as respostas derivadas da questão 7: "Com quais setores mais trabalha/interage? Com qual finalidade ocorre essa interação? Que canais e tecnologias utilizam para essa interação?”.

Quadro 5: Fluxo interno: receptor, canais e tecnologias

\begin{tabular}{|c|l|l|l|}
\hline Participantes & Com quais setores interage? & Com qual finalidade? & $\begin{array}{l}\text { Quais as tecnologias } \\
\text { utilizadas? }\end{array}$ \\
\hline 1 & Gerência / diretoria & $\begin{array}{l}\text { Troca de informação sobre } \\
\text { clientes. }\end{array}$ & E-mail, sistema \\
\hline 2 & Gerência /diretoria & Informar situação do cliente & E-mail. \\
\hline 3 & $\begin{array}{l}\text { Departamento pessoal, } \\
\text { gerência/diretoria, escrita fiscal. }\end{array}$ & $\begin{array}{l}\text { Informação sobre valores da } \\
\text { folha de pagamento. }\end{array}$ & Software, e-mail, \\
\hline 4 & $\begin{array}{l}\text { Departamento pessoal, } \\
\text { gerência/diretoria, departamento } \\
\text { fiscal. }\end{array}$ & $\begin{array}{l}\text { Dados sobre os valores de } \\
\text { impostos e outros pagamentos. }\end{array}$ & $\begin{array}{l}\text { Programa do sistema, e- } \\
\text { mail. }\end{array}$ \\
\hline 5 & $\begin{array}{l}\text { Departamento fiscal, } \\
\text { departamento contábil, processo e } \\
\text { pessoal, gerência. }\end{array}$ & $\begin{array}{l}\text { Informação sobre a vida da } \\
\text { empresa. }\end{array}$ & $\begin{array}{l}\text { Sistema, } \\
\text { software. }\end{array}$ \\
\hline 6 & $\begin{array}{l}\text { Departamento pessoal, } \\
\text { departamento fiscal, processo. }\end{array}$ & $\begin{array}{l}\text { Fechamento mensal, dos } \\
\text { impostos e demais documnetos }\end{array}$ & Sistema, software \\
\hline
\end{tabular}




\begin{tabular}{|l|l|l|l|l|}
\hline 7 & $\begin{array}{l}\text { Departamento fiscal, } \\
\text { departamento pessoal, gerência }\end{array}$ & $\begin{array}{l}\text { Faço as buscas pelas } \\
\text { informações }\end{array}$ & E-mail, software \\
\hline 8 & $\begin{array}{l}\text { Gerência, departamento contábil, } \\
\text { departamento de processo. }\end{array}$ & $\begin{array}{l}\text { Situação que o cliente se } \\
\text { encontra }\end{array}$ & $\begin{array}{l}\text { Software, } \\
\text { sistema. }\end{array}$ & e-mail, \\
\hline
\end{tabular}

Fonte: Elaborado pelo autor.

De acordo com a análise das respostas dos participantes, pode-se observar com quais setores cada participante interage e por qual finalidade isso ocorre, as respostas foram diversas e sucintas referentes à finalidade que ocorre esta interação. Para ilustrar o fluxo de informação interno no que tange aos setores apresenta-se a figura 3 abaixo:

Figura 3 - Fluxo de informação interno.

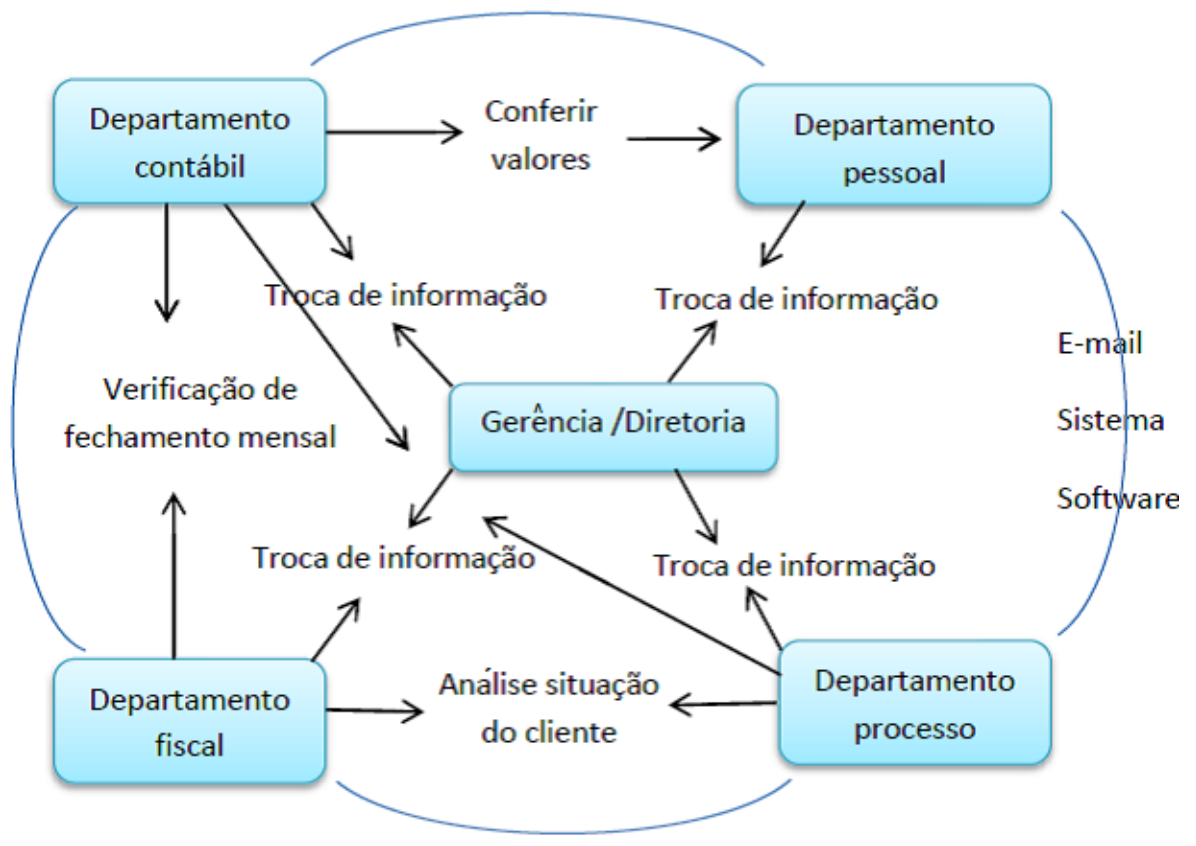

Fonte: Elaborado pelo autor.

O fluxo de informação de setores ocorre formalmente existindo uma interação na elaboração do trabalho. Ocorre que o Departamento Pessoal interage diretamente com a gerência, porém com a Contabilidade existe uma interação através das informações inseridas no sistema, onde o setor de Contabilidade busca informações, mas não há troca de informação entre os participantes devido ao fato de o serviço desenvolvido pelo Departamento Pessoal não precisar de informações de nenhum outro setor, apenas das que são oferecidas pelos clientes e permissão da gerência para resolução de algumas pendências.

Os demais setores interagem entre si, principalmente o departamento contábil que depende do trabalho dos demais setores para finalizar as obrigações contábeis do cliente, devido ao fato de todas as informações geradas nos demais departamentos fazerem parte da vida financeira da empresa. A forma que esta interação acontece é através de e-mail, sistemas e 
software específico. Todos os setores trocam informação com a Gerência/Diretoria, sendo ela o centro do fluxo.

Dando prosseguimento, passa-se para a análise da questão 8: "Existe colaboração entres os níveis estratégicos para a disseminação da informação por todos os setores? Se sim, descreva de que forma acontece. Se não, cite os motivos". Os participantes não responderam de forma muito clara ou sentiram dificuldades para se expressar sobre o assunto abordado, mas entre os oito participantes houve um que a resposta transcreve a opinião de todos:

"Sim, de forma falha, a diretoria e os responsáveis pelos setores transmitem as
informações que são precisas para o desenvolvimento do serviço prestado aos clientes,
dessa forma ocorre a troca de informação entre os setores ou pelo menos a maioria
deles. Existem situações que as informações não são repassadas rapidamente, já que
boa parte da informação é transmitida por e-mail, não são todos que verificam a caixa
de e-mail com frequência, causando certo transtorno e demora em atender o cliente".
(Participante 4).

Por esse motivo percebe-se que mesmo acontecendo a disseminação de informação entres os níveis estratégicos e os setores dos demais níveis, isso ocorre com falha, por falta de colaboração ou comprometimento, neste aspecto todos os participantes concordaram.

Passando-se a análise da questão 9: "Como as informações geradas fluem entre os setores? Como essas informações auxiliam na tomada de decisão? Descreva como você enxerga o fluxo de informação existente na organização", apenas os participantes três, cinco e oito responderam, os participantes um, dois, quatro, seis e sete não opinaram sobre a questão. Entre os que responderam destacou-se a resposta do seguinte participante:

\footnotetext{
"As informações fluem pelos setores conforme a necessidade de cada um ou de acordo com a solicitação do cliente, fazendo com que se busque sanar as dúvidas existentes em sites informativos ou com os resposáveis antes de tomar alguma decisão. Sendo assim as informações que fluem entre os setores, auxiliam na tomada de decisão após ser verificada sua veracidade. Sobre o fluxo de informação pelo que entendi ocorre de forma singela, podendo ser melhorado". (Participante 3).
}

Conforme resposta dos participantes o fluxo de informação nos setores ocorre de acordo com o que se precisa e não de forma contínua, e as informações são transmitidas sem uma necessidade inicial e sim para auxiliar a tomada de decisão de maneira pontual, de forma a deixar os colaboradores atualizados e preparados para qualquer situação.

Por fim a questão 10: "Quais os principais problemas encontrados no fluxo de informação dentro da empresa?”. As respostas são apresentadas no quadro 6. 
Quadro 6: Problemas existentes no fluxo de informação

\begin{tabular}{|c|l|}
\hline Participantes & $\begin{array}{l}\text { Principais problemas encontrados no fluxo de } \\
\text { informação? }\end{array}$ \\
\hline 1 & Comunicação \\
\hline 2 & Comunicação resrita \\
\hline 3 & Falta de comunicação \\
\hline 4 & Comunicação ruim \\
\hline 5 & \\
\hline 6 & Falta de diálogo \\
\hline 7 & Pouca conversa entre as pessoas \\
\hline 8 & Comunicação falha \\
\hline
\end{tabular}

Fonte: Elaborado pelo autor.

Todos os participantes que responderam a questão concordam que o problema central encontrado no fluxo de informação é a comunicação que ocorre de forma falha ou pontual, apenas perante a necessidade de obter ou transmitir uma informação. Todos concordam que se houvesse essa troca mais frequente ou reuniões mensais o fluxo de informação seria mais eficaz. Sintetizando os resultados da pesquisa, apresenta-se de maneira ilustrativa como o fluxo de informação ocorre na organização pesquisada, conforme a Figura 4.

Figura 4 - Fluxo de informação no contexto contábil

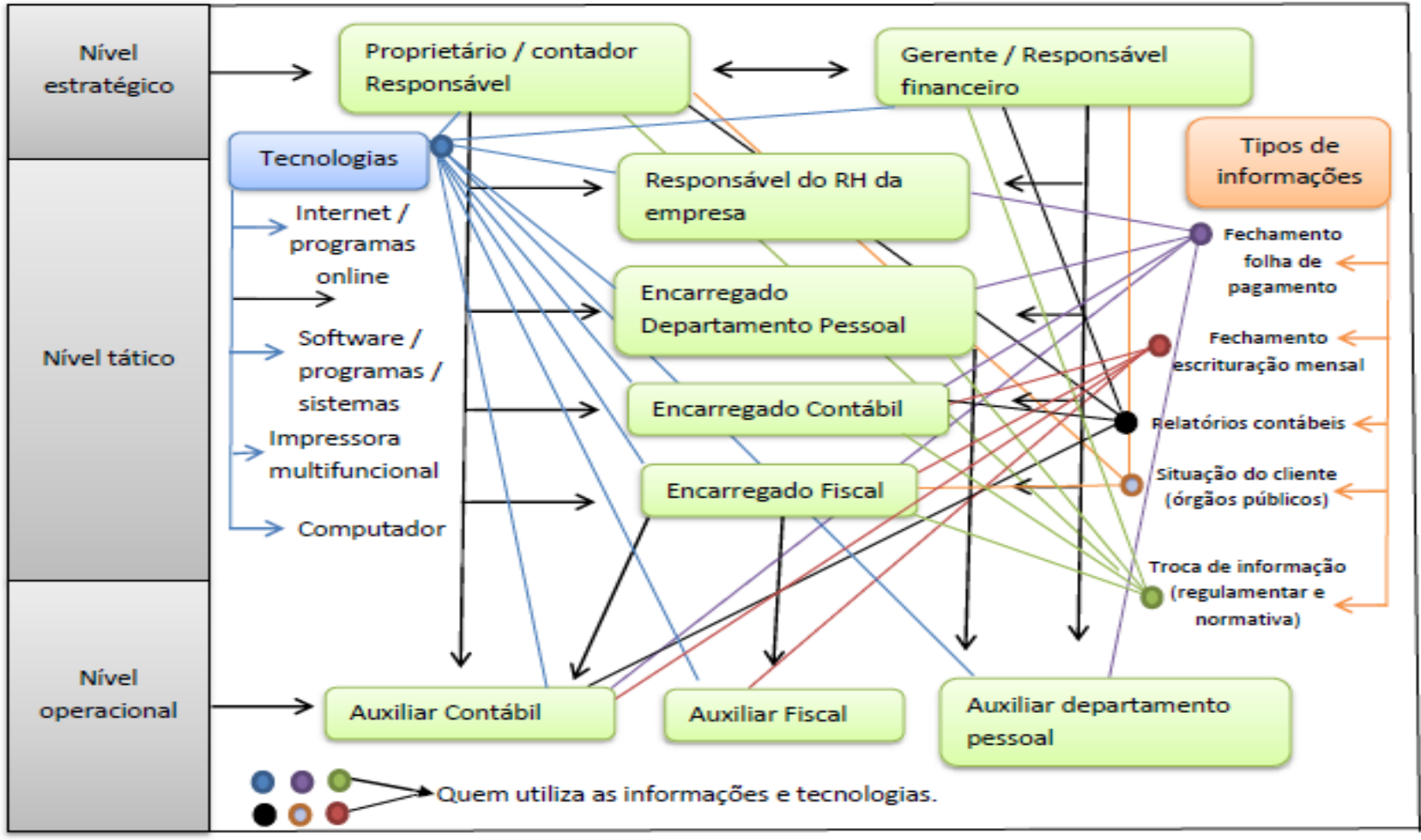

Fonte: Elaborado pelo autor.

O fluxo informacional ocorre de forma a fornecer informações para cada setor de acordo com a necessidade existente, entres os níveis e setores da organização. Se a falta de comunicação não atrapalhasse o fluxo informacional, o mesmo ocorreria de maneira mais 
intensa e constantemente, e fluiria com mais naturalidade, favorecendo tanto o cliente como a tomada de decisão e o posicionamento de cada setor perante alguma eventualidade.

Desta forma, as informações ocorrem sempre através de sistemas, software como auxílio na tomada de decisão, da mesma forma que as informações transmitidas aos clientes ocorrem através de relatório ou documentos emitidos pelos programas utilizados. Percebe-se que a comunicação, ou falta dela, é o maior problema existente e o que mais dificulta o bom andamento do fluxo, já que o suporte utilizado para buscar informações é de confiança, e a organização conta com pelo menos um colaborador de cada setor que sempre faz cursos ou participa de palestras sobre assuntos que são de relevância para o desenvolvimento das atividades.

O que realmente dificulta um bom fluxo informacional dentro da empresa, conforme se infere dos resultados alcançado, é o fato dos funcionários terem receio de transmitir seus conhecimentos para outros, esquecendo que desta forma tornam-se profissionais com desempenho insatisfatório e deixa de colaborar com o pleno desenvolvimento organizacional.

Considera-se que, para trabalhar com informação contábil, deve-se manter o fluxo informacional voltado à construção de conhecimento dos indivíduos e da organização como um todo, e que toda atividade precisa ser pensada nessa perspectiva, para então, poder usufruir dos benefícios que os fluxos de informação podem trazer, como o aprendizado constante e a melhoria dos processos, a compreensão dos ambientes internos e externos e, por fim, o desenvolvimento organizacional. 


\section{Considerações finais}

A pesquisa se debruçou sobre o tema dos fluxos de informação, em que buscou investigar como ocorre o fluxo de informação em uma empresa de contabilidade, por meio da identificação dos tipos de informações que circulam no ambiente interno da organização, e da identificação também de atores, setores, atividades, canais e tecnologias existentes na organização e da descrição dos processos existentes.

Após análise do fluxo de informação dentro da empresa de contabilidade, verificando como flui a informação entre os setores e os níveis da organização, pode-se perceber que a organização citada não utiliza as ideias apresentadas pelos autores citados no trabalho para melhorar seu fluxo informacional, sendo todos os setores responsáveis pelas informações utilizadas na tomada de decisão referente ao que deve ser feito e as informações transmitidas aos clientes.

Desta forma, ao observar o fluxo de informação da empresa, conclui-se que em alguns setores a troca de informação e a interação entre os funcionários fluem de forma mais clara e rápida, mas de forma individual, onde cada um busca apenas pelo que precisa. Existem falhas por falta de colaboração ou de comunicação, insegurança ou falta de conhecimento da importância que o fluxo de informação tem.

Sendo assim, parte das informações administrativas ou gerenciais da empresa é obtida através do sistema interno e por sites governamentais, são transmitidas para setores de acordo com a necessidade existente; da mesma forma ocorre troca de informação entre colaboradores, fazendo com que o fluxo seja usado intensamente em um setor ou no compartilhamento entre dois setores, porém, fragmentado se analisar de forma abrangente em relação a todos os setores e níveis, perdendo a oportunidade de usufruir dos meios eletrônicos e manuais que disponibilizam informações essenciais para o desenvolvimento da organização.

Sugere-se, como forma de melhorar o fluxo de informação, que a empresa pesquisada busque trabalhar o compartilhamento da informação com mais frequência entre seus colaboradores, através de reuniões mensais para que possam expor suas dúvidas e dificuldades, bem como compartilhar novos conhecimentos. Que seja propiciado momento de interação entre todos os setores, mesmo quando a informação utilizada for obtida através do sistema para que o diálogo ocorra entre todos os níveis da organização e a comunicação seja diária, mesmo as mais simples até as situações mais complexas. 
Desse modo, é possível iniciar uma prática virtuosa que possa se desenvolver numa perspectiva de construção de um espaço de conhecimento, tendo em vista a confluência entre o estudo dos fluxos de informação com a temática da gestão do conhecimento. Também, ao formar bases de conhecimento, é possível expandir para sistematizar práticas de gestão de documentos e/ou de memória organizacional, de maneira a preservar e dar um uso mais dinâmico das informações necessárias ao desenvolvimento da organização.

Sabendo que esta pesquisa não esgota o assunto, recomenda-se também que se investigue como ocorre o fluxo informacional através do sistema utilizado pela empresa entre os funcionários, para saber se todos os setores utilizam o sistema em sua totalidade aproveitando ao máximo os recursos disponíveis; e verificar se as informações inseridas no sistema são de fácil compreensão a todos que precisam dele, bem como se existe padronização na utilização do sistema.

Assim, será possível avançar na compreensão do estudo dos fluxos de informação, especificamente no campo da informação contábil, e desse modo contribuir no campo teórico e prático na melhoria dos processos informacionais e nas práticas organizacionais que possam pensar em um desenvolvimento coerente com as novas demandas econômicas e sociais.

\section{Referências}

BEAL, A. Segurança da informação: princípios e as melhores práticas para a proteção dos ativos de informações nas organizações. São Paulo: Atlas, 2008.

CHOO, C. W. A organização do conhecimento. São Paulo: SENAC, 2003.

DAVENPORT, T. H.; PRUSAK, L. Conhecimento empresarial. Rio de Janeiro: Campus: São Paulo: Publifolha,1999.

DRUCKER, P. F. O melhor de Peter Drucker: a administração. São Paulo: Nobel, 2002.

FABRETTI, L. C. Contabilidade tributária. 3. ed. São Paulo: Atlas, 1997.

FISKE, J. Introduction to communication studies. 3. ed. London: Routledge, 2010. 248p.

FLORIANI, V. M. Análise do fluxo informacional como subsídio ao processo de tomada de decisões em órgão municipal de turismo. 2007. 187f. Dissertação (Mestrado em ciência da informação) - Universidade federal de Santa Catarina. Florianópolis, 2007.

GOUVEIA, N. Contabilidade. São Paulo: McGraw-Hill do Brasil, 1978.

LAKATOS, E. M.; MARCONI, M. A. Metodologia científica. 4. ed. São Paulo: Atlas, 1999. 
LAUDON, K. C.; LAUDON, J. P. Sistemas de informação. 4. ed. Rio de Janeiro: LTC,1999.

MACHADO, I.; ROMANINI, V. Semiótica da comunicação: da semiose da natureza à cultura. Revista Famecos, Porto Alegre, v. 17, n. 2, p. 89 - 97, maio/ago, 2010.

MCGEE, J; PRUSAK, L. Gerenciamento estratégico da informação. Rio de Janeiro: Campus, 1994.

OLIVEIRA, M. Manual de contabilidade tributária. 3. ed. São Paulo: Atlas, 2004.

ROSSINI, A. M.; PALMISANO, A. Administração de sistemas de informação e a gestão do conhecimento. São Paulo: Thomson Learning, 2003.

SHANNON, C. E.; WEAVER, W. The mathematical theory of communication. Urbana: University of Illinois Press, 1949.

SMIT, J. W.; BARRETO, A. A. Ciência da informação: base conceitual para a formação do profissional. In: VALENTIM, M. L. (Org). Formação do profissional da informação. São Paulo: Polis, 2002, p 9-23.

VALENTIM, M. L. P.; TEIXEIRA, T. M. C. Fluxos de informação e linguagem em ambientes organizacionais. Informação \& Sociedade, João Pessoa, v. 22, n. 2, p. 151-156, maio/ago. 2012.

WANG, R.; ZIAD, M.; LEE, Y.W. Data quality. Kluwer Academic, 2000.

YAMAMOTO, M. M.; SALOTTI, B. M. Informação contábil: estudos sobre a sua divulgação no mercado de capitais. São Paulo: Atlas, 2006. 